\title{
Yếu tố ảnh hưởng đến sự thành công của dự án trong các tổ chức sản xuất
}

\section{Factors influencing the project success in manufacturing organizations}

\author{
Nguyễn Thúy Quỳnh Loan ${ }^{1 *}$, Nguyễn Vương Chí ${ }^{1}$, Nguyễn Trần Quốc Khanh ${ }^{1}$ \\ ${ }^{1}$ Trường Đại học Bách Khoa, Đại học Quốc gia TP.HCM, Việt Nam \\ *Tác giả liên hệ, Email: ntqloan@ hcmut.edu.vn
}

THÔNG TIN

DOI: $10.46223 / \mathrm{HCMCOUJS.}$ econ.vi.14.3.475.2019

Ngày nhận: 16/07/2019

Ngày nhận lại: 31/07/2019

Duyệt đăng: 01/08/2019

Tù khóa:

dự án sản xuất, mô hình PIP, quản lý dự án, sự thành công của dự án

\section{Keywords:}

manufacturing project, PIP model, project management, project success

\section{TÓM TẮT}

Mục tiêu của bài báo là xác định và đo lường các yếu tố ảnh hưởng đến sự thành công của dự án trong các tổ chức sản xuất. Các yếu tố ảnh hưởng được tham khảo từ mô hình PIP của Slevin và Pinto (1986). Từ 203 mẫu thu thập được, mô hình nghiên cứu được kiểm định và kết quả cho thấy các yếu tố nhiệm vụ dự án, hỗ trợ quản lý cấp cao, lập kế hoạch dự án, tham khảo ý kiến khách hàng, năng lực nhân sự, công việc kỹ thuật, truyền thông và giải quyết vấn đề có ảnh hưởng tích cực đến sự thành công của dự án. Từ đó, bài báo đưa ra những thảo luận và hàm ý quản trị để gia tăng sự thành công của dự án cho các tổ chức sản xuất ở Việt Nam.

\section{ABSTRACT}

The paper aims to identify and measure factors affecting project success in manufacturing organizations. The influential factors are adapted from the PIP model of Slevin and Pinto (1986). From the 203 collected samples, the research model is verified and the result shows that factors positively affecting the project success include project mission, top management support, project planning, client consultation, personnel ability, technical task, communication and trouble-shooting. The paper then provides discussions and managerial implications to enhance the project success for manufacturing organizations in Vietnam.

\section{1. Đặt vấn đề}

Quản lý dự án được xem như là một nguyên tắc quản lý nền tảng cho nhiều hoạt động kinh tế. Trong các ngành công nghiệp sản xuất, việc đầu tư vào các dự án sẽ thúc đẩy hoạt động kinh doanh. Do đó, quản lý dự án được nhấn mạnh như là một quá trình ra quyết định và vận hành các chiến lược và chiến thuật để đưa dự án thành công (Kuen, Zailani, \& Fernando, 2009). 
Các tổ chức cần phải hiểu được đâu là yếu tố thành công quan trọng, đánh giá chúng một cách định lượng và có hệ thống, dự báo các tác động có thể, và sau đó chọn phương pháp thích hợp để quản lý chúng sẽ làm tăng cơ hội thành công cho dự án (Adnan, Yusuwan, Yusuf, \& Bachik, 2014; Baccarini, 2009; Mobey \& Parker, 2002).

Theo Slevin và Pinto (1986), quá trình thực hiện dự án rất phức tạp, thường đòi hỏi sự chú ý sâu rộng về các yếu tố con người, ngân sách và kỹ thuật. Các dự án thường có các yếu tố thành công quan trọng, nếu chúng được quan tâm và quản lý tốt sẽ giúp cải thiện khả năng thực hiện thành công dự án. Ngược lại, nếu các yếu tố này không được thực hiện nghiêm túc có thể dẫn đến sự thất bại của dự án. Kinh doanh ngày nay được vận hành trong điều kiện không chắc chắn cao, có nhiều yếu tố bất ngờ, yêu cầu khách hàng ngày càng tăng, thay đổi các ràng buộc và biến động về nguồn tài nguyên. Do đó, dự án cần phải được quản lý hiệu quả, nếu không khả năng thất bại rất cao.

Các ngành công nghiệp sản xuất và xây dựng đều có rất nhiều dự án, nhưng các dự án thuộc ngành công nghiệp sản xuất được thực hiện nhiều hơn so với các dự án xây dựng. Thực vậy, theo Tổng cục Thống kê (2018), GDP cả năm 2018 của Việt Nam tăng 7,08\%, là mức tăng cao nhất 11 năm trở về đây. Trong khu vực công nghiệp và xây dựng, ngành công nghiệp chế biến, chế tạo tiếp tục là điểm sáng đóng góp chính cho tăng trưởng kinh tế với mức tăng cao $12,98 \%$, tuy thấp hơn mức tăng của năm 2017 nhưng cao hơn nhiều so với mức tăng các năm 2012-2016. Qua đó có thể thấy ngành công nghiệp trong lĩnh vực sản xuất ở Việt Nam đã có sự tăng trưởng đáng kể trong nhiều năm qua. Mặc dù có nhiều dự án sản xuất thành công nhưng cũng còn tồn tại nhiều dự án gặp không ít khó khăn buộc phải dừng hoặc giãn tiến độ (Minh Huyen, 2017). Việc một dự án ngừng sản xuất, chậm tiến độ, tăng ngân sách sẽ gây nhiều hệ lụy về mặt tài chính, lao động, ... cho tổ chức nói riêng và cho nền kinh tế và xã hội nói chung. Chính vì vậy các tổ chức cần phải nhận ra các yếu tố thành công quan trọng của dự án.

Do đó, mục tiêu của bài báo này là xác định và đo lường các yếu tố quan trọng ảnh hưởng đến sự thành công của dự án trong các tổ chức sản xuất ở Việt Nam. Từ đó, bài viết đưa ra những thảo luận và hàm ý quản trị để giúp các tổ chức nâng cao sự thành công cho các dự án sản xuất của họ.

\section{Cơ sở lý thuyết}

\section{Sự thành công của dự án}

Sự thành công của dự án là điểm trọng tâm của quản lý dự án. Do đó, sự thành công của dự án là một trong những ưu tiên hàng đầu của các nhà quản lý dự án và các bên liên quan của dự án. Không có gì đáng ngạc nhiên khi chủ đề này đã thu hút nhiều học giả và nhà quản lý dự án trong nhiều thập kỷ qua và vẫn còn tiếp tục cho đến nay.

Thành công của dự án là mục tiêu cuối cùng của dự án (Chan \& Chan, 2004). Không có định nghĩa chuẩn về tiêu chí đánh giá sự thành công của dự án. Tuy nhiên, các tiêu chí này phải được thống nhất khi bắt đầu dự án để tránh sự khác biệt giữa các bên liên quan (Ahadzie, Proverbs, \& Olomolaiye, 2008). Theo Atkinson (1999), tiêu chí đánh giá sự thành công gồm có 4 khía cạnh (Bảng 1). 


\section{Bảng 1}

Các tiêu chí đánh giá sự thành công của dự án

\begin{tabular}{|c|c|c|c|}
\hline $\begin{array}{l}\text { Tam giác } \\
\text { sắt }\end{array}$ & $\begin{array}{l}\text { Hệ thống } \\
\text { thông tin }\end{array}$ & $\begin{array}{l}\text { Lợi ích của tổ chức } \\
\text { (Lọii ích trụ̣c tiếp) }\end{array}$ & $\begin{array}{l}\text { Lọ̣i ích của các bên liên quan } \\
\text { (Lọ̣i ích gián tiếp) }\end{array}$ \\
\hline $\begin{array}{l}\text { Chi phí } \\
\text { Chất lượng } \\
\text { Thời gian }\end{array}$ & $\begin{array}{l}\text { Khả năng duy trì } \\
\text { Độ tin cậy } \\
\text { Độ giá trị } \\
\text { Sử dụng thông } \\
\text { tin chất lượng }\end{array}$ & $\begin{array}{l}\text { Hiệu suất được cải thiện } \\
\text { Hiệu quả được cải thiện } \\
\text { Lợi nhuận gia tăng } \\
\text { Đáp ứng mục tiêu chiến } \\
\text { lược } \\
\text { Học hỏi tổ chức } \\
\text { Giảm lãng phí }\end{array}$ & $\begin{array}{l}\text { Khách hàng hài lòng } \\
\text { Ảnh hưởng đến môi trường và xã hội } \\
\text { Phát triển nhân sự } \\
\text { Học hỏi tính chuyên nghiệp } \\
\text { Lợi nhuận từ các hợp đồng } \\
\text { Nhà cung cấp vốn, nhóm dự án, ảnh } \\
\text { hưởng kinh tế đến cộng đồng xung } \\
\text { quanh }\end{array}$ \\
\hline
\end{tabular}

Nguồn: Atkinson (1999)

\section{Các yếu tố ảnh hưởng đến sự thành công của dự án}

Nhiều nhà nghiên cứu đã cố gắng xác định các yếu tố ảnh hưởng đến sự thành công của dự án như Slevin và Pinto (1986), Kerzner (1987), Pinto và Slevin (1989), Clarke (1999), Cooke-Davies (2002), Muller và Turner (2003), ... Trong đó, Slevin và Pinto (1986) đã phát triển mô hình PIP (Project Implementation Profile) gồm 10 yếu tố thành công quan trọng (Bảng 2). Các yếu tố này được tham khảo rộng rãi trong nhiều nghiên cứu khi đo lường các yếu tố ảnh hưởng đến sự thành công của dự án (Muller \& Turner, 2005). Ngoài ra, mô hình PIP được phát triển dựa trên các dự án thuộc ngành sản xuất. Do đó, các yếu tố của quản lý dự án được phát triển bởi Slevin và Pinto (1986) sẽ được áp dụng cho nghiên cứu này.

\section{Bảng 2}

Mô hình PIP của Slevin và Pinto (1986)

\begin{tabular}{|l|l|}
\hline Yếu tố & Định nghĩa \\
\hline Nhiệm vụ dự án & Sự rõ ràng ngay từ đầu của mục tiêu và định hướng chung \\
\hline Hỗ trợ của quản lý cấp cao & $\begin{array}{l}\text { Sẵn sàng của quản lý cấp cao về việc cung cấp các nguồn lực cần thiết } \\
\text { và trao quyền để dự án thành công }\end{array}$ \\
\hline Lập kế hoạch dự án & $\begin{array}{l}\text { Xây dựng các đặc điểm kỹ thuật chi tiết cho các bước hành động cụ } \\
\text { thể được yêu cầu để thực hiện dự aan. }\end{array}$ \\
\hline $\begin{array}{l}\text { Tham khảo ý kiến khách } \\
\text { hàng }\end{array}$ & $\begin{array}{l}\text { Giao tiếp, tham vấn và lắng nghe tích cực với tất cả các bên bị ảnh } \\
\text { hương }\end{array}$ \\
\hline Nhân sự & Tuyển dụng, tuyển chọn và đào tạo nhân sự cần thiết cho nhóm dự án \\
\hline Công việc kỹ thuật & $\begin{array}{l}\text { Sự sã̃n có về công nghệ và các bước kỹ thuật cần thiết để thực hiện dự } \\
\text { án }\end{array}$ \\
\hline $\begin{array}{l}\text { Sự chấp nhận của khách } \\
\text { hàng }\end{array}$ & $\begin{array}{l}\text { Sự chấp nhận của khách hàng sử dụng về sản phẩm cuối cùng của dự } \\
\text { án }\end{array}$ \\
\hline
\end{tabular}




\begin{tabular}{|l|l|}
\hline Yếu tố & Định nghĩa \\
\hline Giám sát và phản hồi & $\begin{array}{l}\text { Cung cấp thông tin kiểm soát toàn diện một cách kịp thời ở từng giai } \\
\text { đoạn trong quá trình thực hiện }\end{array}$ \\
\hline Truyền thông & $\begin{array}{l}\text { Cung cấp một mạng lưới thông tin thích hợp và dữ liệu cần thiết cho } \\
\text { tất cả các tác nhân chính trong quá trình thực hiện dự án }\end{array}$ \\
\hline Giải quyết vấn đề & Khả năng xử lý khủng hoảng bất ngờ và sai lệch so với kế hoạch \\
\hline
\end{tabular}

Nguồn: Kết quả phân tích dữ liệu của nhóm nghiên cứu

\section{Nhiệm vụ dụ án}

Mục tiêu dự án rõ ràng sẽ giúp nâng cao khả năng thành công của dự án (Pinto \& Slevin, 1989). Hơn nữa, nó còn giúp thúc đẩy sự hợp tác trong nhóm dự án và các bên liên quan, thậm chí có thể dẫn đến giảm thời gian thực hiện dự án (Lynn, Skov, \& Abel, 1999). Nhiệm vụ dự án là yếu tố rất quan trọng liên quan đến thành công trong toàn bộ vòng đời dự án. Sự rõ ràng ban đầu về mục tiêu và định hướng của dự án là những yếu tố quan trọng cho các dự án thành công trong lĩnh vực sản xuất (Kuen et al., 2009). Điều quan trọng là mục tiêu dự án phù hợp với mục tiêu chung của tổ chức và được làm rõ cho nhóm dự án. Nghiên cứu của Iram, Khan, và Sherani (2016) cũng khẳng định việc xác định nhiệm vụ dự án một cách rõ ràng sẽ có tác động tích cực đến sự thành công của dự án trong ngành sản xuất và xây dựng. Vì vậy, giả thuyết H1 được đề xuất như sau:

\section{H1: Nhiệm vụ dụ án có ảnh hưởng tích cực đến sụ thành công của dụ án}

\section{Hỗ trọ’ của quản lý cấp cao}

Hỗ trợ của quản lý cấp cao thường là việc cung cấp đủ nguồn lực cho dự án, chia sẻ trách nhiệm với nhóm dự án, liên lạc với chính quyền và hỗ trợ nhóm dự án trong thời kỳ khủng hoảng hoặc các tình huống bất ngờ. Với sự hỗ trợ tích cực từ ban lãnh đạo hay các phòng ban liên quan thì một dự án có thể sẽ giảm bớt khó khăn khi phải đối mặt với nhiều vấn đề mà nhóm dự án chưa từng đối mặt (Pinto \& Slevin, 1989; Yeoh \& Koronios, 2010). Các nghiên cứu của Kuen và cộng sự (2009) và Iram và cộng sự (2016) cũng cho thấy sự hỗ trợ của quản lý cấp cao ảnh hưởng tích cực đến thành công của dự án. Do đó, giả thuyết H2 được đề xuất như sau:

H2: Hỗ trợ của quản lý cấp cao có ảnh hưởng tích cực đến sụ thành công của dụ án

\section{Lập kế hoạch dụ án}

Để một dự án khởi đầu, nó cần một kế hoạch khả thi, chu đáo. Tất cả các hoạt động cần thiết để thực hiện dự án cần phải được lên lịch. Hơn nữa, tất cả những nguồn nhân lực cần thiết, tiền bạc, thời gian và các nguồn lực khác để hoàn thành dự án cũng phải được phân bổ. Lập kế hoạch chính là cơ sở để đo lường sự sai lệch của thực tế triển khai dự án và dựa trên đó để có những hành động hiệu chỉnh phù hợp (Larson \& Gray, 2018). Để dự án thành công, cần có kế hoạch cụ thể để hướng dẫn nhóm dự án khi triển khai xuyên suốt vòng đời dự án (Fraz, Waris, Afzal, Jamil, \& Syed, 2016; Iram et al., 2016; Pinto \& Slevin, 1989). Do đó, giả thuyết H3 được đề xuất như sau:

\section{H3: Lập kế hoạch dụ án có ảnh hưởng tích cưc đến sụ thành công của dụ án}




\section{Tham khảo ý kiến khách hàng}

Khách hàng thường là người dùng cuối của dự án. Việc giao tiếp và trao đổi thông tin giữa khách hàng và nhóm dự án nên được thực hiện trong suốt vòng đời dự án. Điều này đảm bảo cho dự án vẫn nằm trong phạm vi ban đầu và cuối cùng sẽ đáp ứng nhu cầu của khách hàng về thời gian, chất lượng và chi phí (Pinto \& Slevin, 1989). Việc giao tiếp giữa nhóm dự án và khách hàng được đánh giá là một yếu tố quan trọng để dự án thành công (Iram et al., 2016; Pinto \& Dominguez, 2012). Do đó, giả thuyết $\mathrm{H} 4$ được đề xuất như sau:

H4: Tham khảo ý kiến khách hàng có ảnh hưởng tích cực đến sụ thành công của dụ án

\section{Năng lục nhân sụ}

Nhân sự dự án có năng lực có ý nghĩa quan trọng đối với thành công dự án. Một nhóm dự án có năng lực bao gồm nhà quản lý dự án và các thành viên được lựa chọn, đào tạo và sở hữu các kỹ năng, kiến thức và kinh nghiệm cần thiết để xử lý các yêu cầu của dự án. Khi dự án hoàn thành và sau đó được giới thiệu cho khách hàng, khả năng thuyết phục để bán sản phẩm của dự án trở nên rất quan trọng nhằm đảm bảo rằng khách hàng sẽ chấp nhận (Kuen et al., 2009). Vai trò quan trọng của nhà quản lý dự án trong quản lý nhân sự là việc tạo động lực và cảm hứng cho nhóm dự án (Fraz et al., 2016). Năng lực của thành viên nhóm dự án cũng đóng vai trò rất quan trọng trong sự thành công của dự án (Iram et al., 2016; Kuen et al., 2009; Pinto \& Slevin, 1989). Do đó, giả thuyết H5 được đề xuất như sau:

\section{H5: Năng lực nhân sự có ảnh hưởng tích cực đến sự thành công của dụ án}

\section{Công việc kỹ thuật}

Sự sẵn có về công nghệ và kỹ năng kỹ thuật là rất cần thiết để đáp ứng các mục tiêu của dự án. Tổ chức cần phải sở hữu các nguồn nhân lực kỹ thuật phù hợp và các tài nguyên kỹ thuật cần thiết để phát triển dự án (Pinto \& Slevin, 1989). Nghiên cứu của Iram và cộng sự (2016) cho thấy công việc kỹ thuật có quan hệ tích cực đối với sự thành công của các dự án. Do đó, giả thuyết $\mathrm{H} 6$ được đề xuất như sau:

\section{H6: Công việc kỹ thuật có ảnh hưởng tích cực đến sự thành công của dự án}

\section{Truyền thông}

Truyền thông tốt đóng một vai trò quan trọng đối với thành công của dự án (Pinto \& Dominguez, 2012). Truyền thông tốt sẽ giúp chia sẻ thông tin hiệu quả (như mục tiêu của dự án, thay đổi các chính sách và thủ tục, các báo cáo...) giữa nhóm dự án, tổ chức mẹ, khách hàng và các đối tác liên quan và đây chính là yếu tố đảm bảo thành công trong quá trình thực hiện dự án (Fraz et al., 2016; Iram et al., 2016; Pinto \& Slevin, 1989). Do đó, giả thuyết H7 được đề xuất như sau:

\section{H7: Truyền thông có ảnh hưởng tích cưc đến sự thành công của dụ án}

\section{Giải quyết vấn đề}

Không có dự án nào được thực hiện mà không gặp bất kỳ vấn đề nào. Việc xử lý các vấn đề diễn ra liên tục ở mỗi giai đoạn trong quá trình thực hiện dự án. Điều quan trọng là mỗi thành viên trong nhóm dự án có khả năng làm việc như là một người phát hiện các vấn đề. Trên thực tế, mỗi nhóm dự án nên có những người có năng lực kỹ thuật và quản lý để nhận diện và giải quyết các vấn đề xảy ra bất cứ khi nào hay bất cứ nơi nào (Slevin \& Pinto, 1989). Việc nhận diện được các rủi ro hay vấn đề cho phép các nhà quản lý có các đối sách phù hợp nhằm 
làm giảm hay tránh được ảnh hưởng tiêu cực của chúng đến thời gian, phạm vi và ngân sách dự án (Junior, Silva, \& Pacifico, 2017). Nghiên cứu của Iram và cộng sự (2016) đã chứng minh sự tồn tại mối quan hệ tích cực giữa giải quyết vấn đề với sự thành công của các dự án. Do đó, giả thuyết H8 được đề xuất như sau:

H8: Giải quyết vấn đề có ảnh hưởng tích cưc sự thành công của dự án

Trong nghiên cứu này không đề cập tới 2 yếu tố trong mô hình PIP là sự chấp nhận của khách hàng, giám sát và phản hồi. Thực tế, khi tiến hành phỏng vấn sâu, những người được phỏng vấn cho rằng các yếu tố này không đứng một mình mà chúng được bao hàm trong các yếu tố khác như là tham khảo ý kiến khách hàng, truyền thông. Điều này cũng tương đồng với kết quả nghiên cứu của Kuen và cộng sự (2009). Do đó, 2 yếu tố này không được khuyến khích đưa vào trong mô hình nghiên cứu.

Mô hình nghiên cứu

Dựa trên 8 giả thuyết được đề xuất ở trên, mô hình nghiên cứu được thể hiện trong Hình 1.

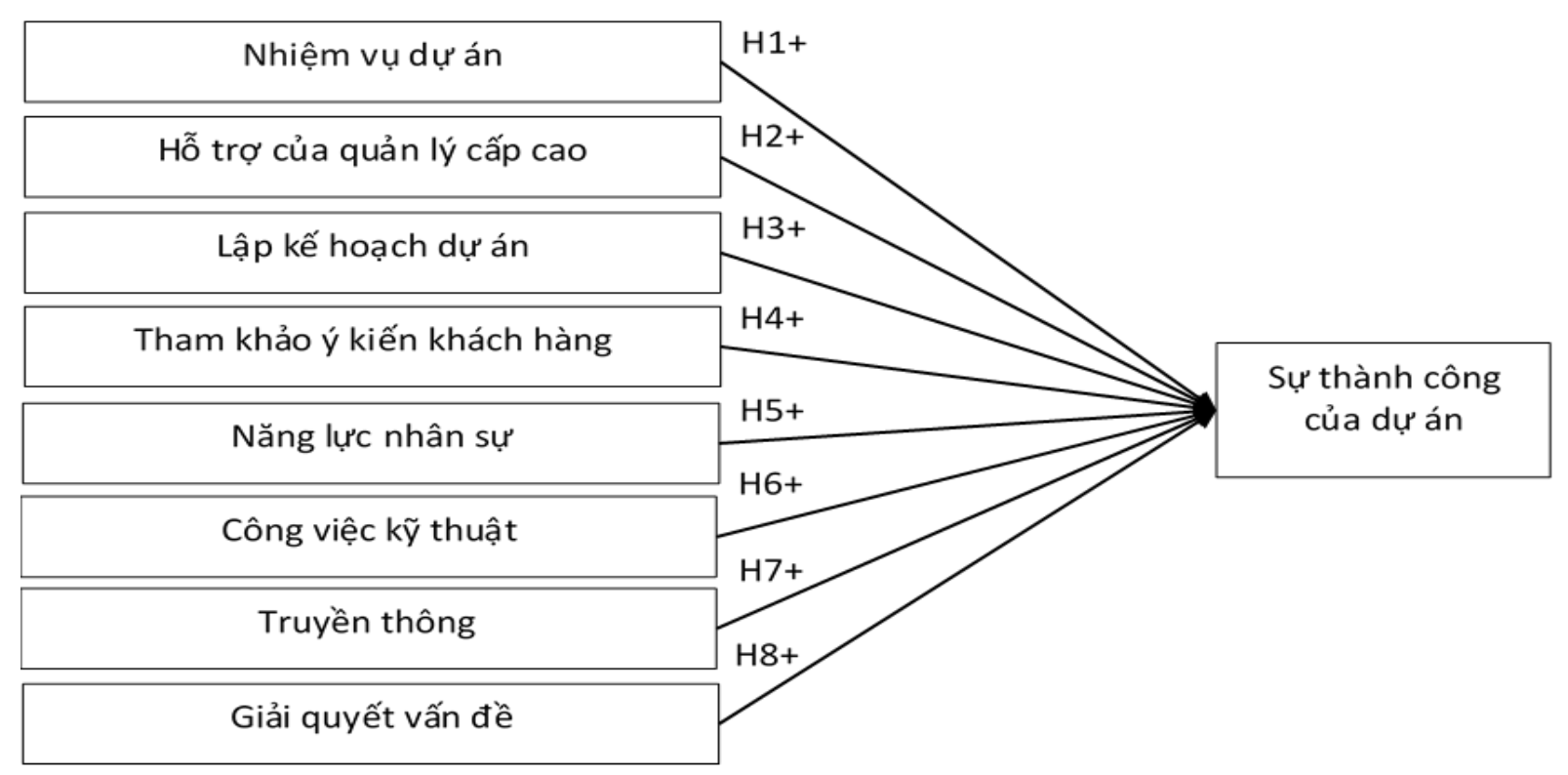

Hình 1: Mô hình nghiên cứu

\section{Phương pháp nghiên cứu}

Phương pháp nghiên cứu được thực hiện thông qua 2 bước: nghiên cứu sơ bộ và nghiên cứu chính thức. Nghiên cứu so bộ được tiến hành bằng cách phỏng vấn sâu với 10 nhà quản lý và thành viên nhóm dự án của tổ chức sản xuất dựa trên 41 biến quan sát được tham khảo chính từ mô hình PIP của Slevin và Pinto (1986) và Atkinson (1999). Từ kết quả phỏng vấn sâu, có 35 biến quan sát sau khi hiệu chỉnh và chọn lọc đã được đưa vào nghiên cứu chính thức (Bảng 3 ). Nghiên cưu định lượng được thực hiện thông qua việc khảo sát theo phương pháp lấy mẫu thuận tiện. Đối tượng khảo sát là các nhà quản lý/điều hành dự án và thành viên nhóm dự án thuộc các tổ chức sản xuất ở TP. HCM, Bình Dương và Đồng Nai. Theo Hair, Black, Babin, và Anderson (2014), tỷ lệ quan sát/biến đo lường tối thiểu là 5:1. Nghiên cứu có 35 biến đo lường nên số mẫu dự kiến là 5 x $35=175$. Thực tế, tổng số lượng mẫu hợp lệ thu thập được là 203. Bảng câu hỏi sử dụng thang đo dạng Likert 5 điểm được sử dụng từ 1 (hoàn toàn không đồng ý) đến 5 (hoàn 
toàn đồng ý). Dữ liệu thu thập được tiến hành sàng lọc và xử lý dữ liệu bằng phần mềm SPSS thông qua các phân tích Cronbach's Alpha, nhân tố khám phá (EFA), tương quan và hồi quy đa biến.

\section{Bảng 3}

Thang đo chính thức

\begin{tabular}{|c|c|}
\hline Biến quan sát & Mã biến \\
\hline Nhiệm vụ dự án & NVDA \\
\hline Mục tiêu của dự án $X$ phù hợp với mục tiêu chung của tổ chức & NVDA1 \\
\hline Mục tiêu của dự án $X$ được xác định rõ ràng đối với nhóm dự án & NVDA2 \\
\hline Khi mục tiêu của dự án $X$ đạt được sẽ mang lại lợi ích cho tổ chức & NVDA3 \\
\hline Hỗ trợ của quản lý cấp cao & HTCC \\
\hline Quản lý cấp cao luôn đáp ứng yêu cầu về nguồn lực cho dự án X khi cần thiết & HTCC4 \\
\hline Quản lý cấp cao chia sẻ trách nhiệm với nhóm dự án $\mathrm{X}$ & HTCC5 \\
\hline $\begin{array}{l}\text { Quản lý cấp cao quy định rõ ràng quyền hạn và trách nhiệm đối với các thành } \\
\text { viên trong dự án X }\end{array}$ & HTCC6 \\
\hline $\begin{array}{l}\text { Quản lý cấp cao hỗ trợ tích cục cho các thành viên trong dụ án X khi có khủng } \\
\text { hoảng xảy ra* }\end{array}$ & HTCC7 \\
\hline Lập kế hoạch dự án & KHDA \\
\hline Kế hoạch về thời gian được lập chi tiết cho dự án $\mathrm{X}$ & KHDA8 \\
\hline Ngân sách chi tiết được lập cho dự án $X$ & KHDA9 \\
\hline $\begin{array}{l}\text { Nhu cầu về nhân sự then chốt (ai, ở đâu,...) được xác định rõ ràng trong kế } \\
\text { hoạch của dự án } X\end{array}$ & KHDA10 \\
\hline Tham khảo ý kiến khách hàng & YKKH \\
\hline Khách hàng có cơ hội trao đổi thông tin trong các giai đoạn thực hiện dự án $\mathrm{X}$ & YKKH11 \\
\hline Khách hàng luôn tuân thủ việc cung cấp thông tin cho dự án $\mathrm{X}$ & YKKH12 \\
\hline Các nội dung công việc quan trọng của dự án $\mathrm{X}$ được thảo luận với khách hàng & YKKH13 \\
\hline Thông tin của khách hàng cung cấp được cập nhật trong kế hoạch dư án $X^{*}$ & YKKH14 \\
\hline Năng lực nhân sụ̣ & NLNS \\
\hline Nhân viên hiểu rõ vai trò của họ trong dự án $X$ & NLNS15 \\
\hline Nhân viên hiểu rõ những công việc mà họ sẽ thực hiện trong dự án $X$ & NLNS16 \\
\hline Nhà quản lý của dụ án X có kỹ năng kỹ thuật phù hợp* & NLNS17 \\
\hline Nhà quản lý của dụ án X có kỹ năng giao tiếp hiệu quả* & NLNS18 \\
\hline Nhà quản lý của dự án $X$ có kỹ năng quản lý thích hợp & NLNS19 \\
\hline $\begin{array}{l}\text { Nhà quản lý của dự án } X \text { có khả năng động viên và duy trì sự gắn kết giữa các } \\
\text { thành viên của dự án } X\end{array}$ & NLNS20 \\
\hline
\end{tabular}




\begin{tabular}{|c|c|}
\hline Biến quan sát & Mã biến \\
\hline Công việc kỹ thuật & CVKT \\
\hline $\begin{array}{l}\text { Dự án } \mathrm{X} \text { có nhân sự có chuyên môn kỹ thuật cao để sử dụng các công nghệ/kỹ } \\
\text { thuật trong quá trìh thực hiện dự án X }\end{array}$ & CVKT21 \\
\hline Công nghệ/kỹ thuật được sử dụng trong dự án X hoạt động hiệu quả & CVKT22 \\
\hline $\begin{array}{l}\text { Công nghệ/kỹ thuật để thực hiện dự án X (trang thiết bị, phương tiện, nguyên vật } \\
\text { liệu...) được chọn lựa thích hợp cho quá trình thực hiện dự án X. }\end{array}$ & CVKT23 \\
\hline Công nghệ/kỹ thuật mới nhất luôn được áp dụng vào quá trình thực hiện dự án $\mathrm{X}$ & CVKT24 \\
\hline Truyền thông & TTDA \\
\hline $\begin{array}{l}\text { Khi cá nhân/nhóm có yêu cầu về những thông tin cần thiết liên quan đến dự án } \mathrm{X} \\
\text { thì luôn nhận được phản hồi nhanh chóng }\end{array}$ & TTDA25 \\
\hline $\begin{array}{l}\text { Kết quả của các cuộc họp trong quá trình thực hiện dự án } X \text { luôn được công bố } \\
\text { và thông tin đến các thành viên liên quan }\end{array}$ & TTDA26 \\
\hline $\begin{array}{l}\text { Các cá nhân/nhóm liên quan đến dự án } X \text { đều biết cách truyền thông những vấn } \\
\text { đề của dự án X }\end{array}$ & TTDA27 \\
\hline Giải quyết vấn đề & GQVD \\
\hline $\begin{array}{l}\text { Khi dự án } X \text { có sự cố, nhà quản lý của dự án } X \text { luôn sẵn sàng nhận sự trợ giúp từ } \\
\text { nhiều người không liên quan đến dự án X }\end{array}$ & GQVĐ28 \\
\hline $\begin{array}{l}\text { Nhóm dừ án thường tổ chíc cuộc họp "động não" đểxác định vấn đề có thể xảy } \\
\text { ra và đề ra cách thức giäi quyết chúng }\end{array}$ & GQVÐ29 \\
\hline $\begin{array}{l}\text { Khi dự án } X \text { gặp khó khăn, thành viên của dự án } X \text { biết chính xác cần phải nhận } \\
\text { được trợ giúp từ đâu }\end{array}$ & GQVĐ30 \\
\hline $\begin{array}{l}\text { Các vấn đề phát sinh trong quá trình thực hiện dự án } \mathrm{X} \text { luôn được giải quyết kịp } \\
\text { thời và triệt đề }\end{array}$ & GQVĐ31 \\
\hline Sự thành công của dự án & TCDA \\
\hline Dự án $\mathrm{X}$ hoàn thành đúng thời hạn & TCDA32 \\
\hline Dự án $\mathrm{X}$ hoàn thành trong ngân sách được phân bổ & TCDA33 \\
\hline Dự án $X$ đáp ứng những yêu cầu kỹ thuật & TCDA34 \\
\hline Dự án $\mathrm{X}$ đáp ứng được yêu cầu của các bên liên quan & TCDA35 \\
\hline
\end{tabular}

* Các biến bị loại khi phân tích EFA

Nguồn: Kết quả phân tích dữ liệu của nhóm nghiên cứu

\section{Kết quả nghiên cứu}

\section{Mô tả mẫu}

Nghiên cứu đã thu thập được 203 bảng câu hỏi hợp lệ. Thống kê mẫu khảo sát được trình bày ở Bảng 4. 


\section{Bảng 4}

Thông tin chung về mẫu khảo sát

\begin{tabular}{|l|r|r|l|r|r|}
\hline \multicolumn{1}{|c|}{ Địa điểm doanh nghiệp } & Tần số & Tỷ lệ (\%) & Ngành sản xuất & Tần số & Tỷ lệ (\%) \\
\hline Tp.HCM & 149 & 73,4 & Thép & 5 & 2,5 \\
\hline Đồng Nai & 26 & 12,8 & Điện & 6 & 3 \\
\hline Bình Dương & 28 & 13,8 & Cơ khí & 43 & 21,2 \\
\hline \multicolumn{1}{|c|}{ Dự án tham gia gần nhất } & & & Giấy & 9 & 4,4 \\
\hline Phát triển sản phầm mới & 149 & 73,4 & Nhựa & 34 & 16,7 \\
\hline Giới thiệu quy trình mới & 9 & 4,4 & Dệt may & 46 & 22,7 \\
\hline Cải tiến chất lượng & 31 & 15,3 & Cao su & 11 & 5,4 \\
\hline Cải tiến vận hành & 14 & 6,9 & Bao bì & 31 & 15,3 \\
\hline & & & Da & 9 & 4,4 \\
\hline & & & Sơn & 9 & 4,4 \\
\hline
\end{tabular}

Nguồn: Kết quả phân tích dữ liệu của nhóm nghiên cứu

\section{Đánh giá độ tin cậy}

Có 35 biến quan sát của 9 nhân tố được đưa vào phân tích. Kết quả đánh giá độ tin cậy thang đo bằng hệ số Cronbach's Alpha cho thấy các hệ số này có giá trị từ 0,801 đến 0,914 đều lớn hơn 0,7 và đồng thời các biến quan sát của các thang đo đều có tương quan biến-tổng từ 0,672 đến 0,864 lớn hơn 0,3 (Bảng 5). Do đó có thể kết luận rằng các thang đo đều đạt độ tin cậy.

\section{Phân tích nhân tố khám phá}

Sau khi các thang đo đều đạt độ tin cậy, 35 biến quan sát tiếp tục được đưa vào phân tích nhân tố khám phá (EFA) để kiểm định độ giá trị của thang đo (giá trị hội tụ và giá trị phân biệt). Kết quả phân tích EFA có 5 biến bị loại (Bảng 3) thuộc các yếu tố Hỗ trợ quản lý cấp cao (HTCC07), Tham khảo ý kiến khách hàng (YKKH14), Năng lực nhân sự (NLNS17, NLNS18) và Giải quyết vấn đề (GQVD29) vì chúng có hệ số tải nhân tố nhỏ hơn 0,5 . Các biến được giữ lại đạt được giá trị hội tụ (hệ số tải $\geq 0,5$ ) và giá trị phân biệt (sự khác biệt giữa các nhân tố $\geq$ 0,3 ). Sau phân tích EFA có 9 yếu tố được trích ra từ 30 biến quan sát (Bảng 5 ) được đưa vào kiểm tra tương quan và phân tích hồi quy đa biến để kiểm định các giả thuyết nghiên cứu.

\section{Bảng 5}

Kết quả đánh giá độ tin cậy và phân tích nhân tố khám phá

\begin{tabular}{|l|c|l|l|l|l|l|l|l|l|}
\hline & NVDA & HTCC & KHDA & YKKH & NLNS & CVKT & TTDA & GQVD & TCDA \\
\hline NVDA01 & 0,712 & & & & & & & & \\
\hline NVDA02 & 0,889 & & & & & & & & \\
\hline NVDA03 & 0,873 & & & & & & & & \\
\hline HTCC04 & & 0,938 & & & & & & & \\
\hline HTCC05 & & 0,943 & & & & & & & \\
\hline HTCC06 & & 0,913 & & & & & & & \\
\hline KHDA08 & & & 0,788 & & & & & & \\
\hline KHDA09 & & & 0,951 & & & & & & \\
\hline
\end{tabular}




\begin{tabular}{|c|c|c|c|c|c|c|c|c|c|}
\hline & NVDA & HTCC & KHDA & YKKH & NLNS & CVKT & TTDA & GQVD & TCDA \\
\hline KHDA10 & & & 0,819 & & & & & & \\
\hline YKKH11 & & & & 0,923 & & & & & \\
\hline YKKH12 & & & & 0,946 & & & & & \\
\hline YKKH13 & & & & 0,619 & & & & & \\
\hline NLNS15 & & & & & 0,886 & & & & \\
\hline NLNS16 & & & & & 0,778 & & & & \\
\hline NLNS19 & & & & & 0,850 & & & & \\
\hline NLNS20 & & & & & 0,769 & & & & \\
\hline CVKT21 & & & & & & 0,860 & & & \\
\hline CVKT22 & & & & & & 0,722 & & & \\
\hline CVKT23 & & & & & & 0,748 & & & \\
\hline CVKT24 & & & & & & 0,723 & & & \\
\hline TTDA25 & & & & & & & 0,789 & & \\
\hline TTDA26 & & & & & & & 0,886 & & \\
\hline TTDA27 & & & & & & & 0,883 & & \\
\hline GQVD28 & & & & & & & & 0,784 & \\
\hline GQVD30 & & & & & & & & 0,800 & \\
\hline GQVD31 & & & & & & & & 0,904 & \\
\hline TCDA32 & & & & & & & & & 0,855 \\
\hline TCDA33 & & & & & & & & & 0,808 \\
\hline TCDA34 & & & & & & & & & 0,840 \\
\hline TCDA35 & & & & & & & & & 0,761 \\
\hline $\begin{array}{c}\text { Cronbach's } \\
\text { Alpha }\end{array}$ & 0,872 & 0,860 & 0,908 & 0,801 & 0,827 & 0,855 & 0,891 & 0,803 & 0,914 \\
\hline Eigenvalue & 9,786 & 3,592 & 2,273 & 1,998 & 1,882 & 1,55 & 1,205 & 1,143 & 1,001 \\
\hline
\end{tabular}

Nguồn: Kết quả xử lý từ dữ liệu điều tra

\section{Phân tích tương quan và hồi quy đa biến}

Phân tích tương quan cho thấy các yếu tố độc lập có hệ số tương quan dương từ 0,120 đến 0,603 với yếu tố phụ thuộc và hầu hết đều có ý nghĩa về mặt thống kê. Tiếp theo, nghiên cứu tiến hành phân tích hồi quy đa biến để kiểm định mô hình nghiên cứu. Kết quả cho thấy $\mathrm{R}^{2}$ hiệuchinh $=0,566$ (Bảng 6), nghĩa là các yếu tố độc lập trong mô hình nghiên cứu giải thích được $56,6 \%$ sự biến thiên của yếu tố thành công của dự án. Bảng 8 trình bày các hệ số hồi quy chuẩn hóa đều có giá trị dương từ 0,100 đến 0,262 và đạt ý nghĩa thống kê (giá trị Sig. đều nhỏ hơn $5 \%$ ). Điều này cho thấy mối quan hệ tích cực giữa các yếu tố độc lập và yếu tố phụ thuộc. Kết quả kiểm định cũng cho thấy không có hiện tượng đa cộng tuyến xảy ra do các yếu tố độc lập đều có hệ số VIF (Variance Inflation Factor) nhỏ hơn 2 (Bảng 8). Như vậy, tất cả các giả thuyết của mô hình đều được ủng hộ. 


\section{Bảng 6}

Tóm tắt mô hình

\begin{tabular}{|c|c|c|c|c|}
\hline Model & R & R Square & Adjusted R Square & Std. Error of the Estimate \\
\hline 1 & $0,764^{\mathrm{a}}$ & 0,583 & 0,566 & 0,59557 \\
\hline
\end{tabular}

a. Predictors: (Constant), NVDA, HTCC, KHDA, YCKH, NLNS, CVKT, TTDA, GQVD.

Nguồn: Kết quả xử lý từ dữ liệu điều tra

\section{Bảng 7}

ANOVA $^{\mathrm{a}}$

\begin{tabular}{|l|l|r|r|r|r|c|}
\hline \multicolumn{2}{|c|}{ Model } & Sum of Squares & \multicolumn{1}{c|}{ df } & Mean Square & F & Sig. \\
\hline \multirow{3}{*}{1} & Regression & 96,373 & 8 & 12,407 & 33,963 & $0,000^{\mathrm{b}}$ \\
\cline { 2 - 7 } & Residual & 68,812 & 194 & 0,355 & & \\
\cline { 2 - 7 } & Total & 165,185 & 202 & & & \\
\hline
\end{tabular}

a. Dependent Variable: TCDA

b. Predictors: (Constant), NVDA, HTCC, KHDA, YCKH, NLNS, CVKT, TTDA, GQVD.

Nguồn: Kết quả xử lý từ dữ liệu điều tra

\section{Bảng 8}

Hệ số hồi quy

\begin{tabular}{|c|c|c|c|c|c|c|c|c|}
\hline & \multirow{2}{*}{ Model } & \multicolumn{2}{|c|}{$\begin{array}{c}\text { Unstandardized } \\
\text { Coefficients } \\
\end{array}$} & \multirow{2}{*}{$\begin{array}{c}\text { Standardized } \\
\text { Beta }\end{array}$} & \multirow{2}{*}{$\mathbf{t}$} & \multirow{2}{*}{ Sig. } & \multicolumn{2}{|c|}{ Collinearity } \\
\hline & & B & $\begin{array}{l}\text { Std. } \\
\text { Error }\end{array}$ & & & & Tolerance & VIF \\
\hline \multirow{9}{*}{1} & (Constant) & $-0,517$ & 0,260 & & $-1,991$ & & & \\
\hline & NVDA & 0,157 & 0,058 & 0,157 & 2,721 & 0,007 & 0,645 & 1,550 \\
\hline & HTCC & 0,071 & 0,033 & 0,106 & 2,139 & 0,034 & 0,877 & 1,140 \\
\hline & KHDA & 0,247 & 0,057 & 0,262 & 4,345 & 0,000 & 0,591 & 1,693 \\
\hline & YCKH & 0,074 & 0,036 & 0,100 & 2,056 & 0,041 & 0,908 & 1,102 \\
\hline & NLNS & 0,238 & 0,060 & 0,245 & 3,969 & 0,000 & 0,562 & 1,780 \\
\hline & CVKT & 0,099 & 0,043 & 0,133 & 2,340 & 0,020 & 0,663 & 1,508 \\
\hline & TTDA & 0,109 & 0,053 & 0,108 & 2,043 & 0,042 & 0,771 & 1,297 \\
\hline & GQVD & 0,169 & 0,068 & 0,137 & 2,495 & 0,013 & 0,710 & 1,408 \\
\hline
\end{tabular}

a. Dependent Variable: TCDA

Nguồn: Kết quả xử lý từ dữ liệu điều tra

\section{Thảo luận kết quả và hàm ý quản trị}

Kết quả kiểm định mô hình lý thuyết cho thấy tất cả các giả thuyết trong mô hình nghiên cứu đều được ủng hộ. Nghĩa là tất cả các yếu tố nhiệm vụ dự án, hỗ trợ của quản lý cấp cao, lập kế hoạch dự án, tham khảo ý kiến của khách hàng, năng lực nhân sự, công việc kỹ thuật, truyền thông, giải quyết vấn đề đều tác động tích cực đến sự thành công của dự án.

Lập kế hoạch dư án (KHDA) có tác động mạnh nhất lên sự thành công của dự án (H3) với hệ số $\beta=0,262$ và Sig. $=0,000<5 \%$. Điều này cho thấy việc lập một kế hoạch cho dự án là một vấn đề rất quan trọng và có tính quyết định đến sự thành công của dự án. Do đó, ban/nhóm 
quản lý dự án cần phải thiết lập một kế hoạch dự án rõ ràng và hợp lý về thời gian, nguồn lực và ngân sách. Các phần mềm lập kế hoạch và quản lý tiến độ dự án nên áp dụng để thuận lợi cho điều chỉnh kế hoạch cho phù hợp với thực tế.

Năng lự nhân sụ (NLNS) có tác động mạnh thứ hai lên sự thành công của dự án (H5) với hệ số $\beta=0,245$ và Sig. $=0,000<5 \%$. Việc các nhân viên tham gia vào dự án hiểu rõ vai trò của mình, hiểu rõ những hoạt động mà họ cần thực hiện cùng với việc nhà quản lý dự án có kỹ năng quản lý và có khả năng động viên, gắn kết các thành viên sẽ làm tăng sự thành công của dự án. Do vậy, để nâng cao năng lực nhân sự cho dự án, ban/nhóm quản lý dự án cần xây dựng ma trận trách nhiệm để mỗi thành viên hay bộ phận chức năng liên quan hiểu rõ được nhiệm vụ/trách nhiệm của họ trong dự án và từ đó có thể phối hợp nhịp nhàng với nhau trong quá trình thực hiện dự án. Ngoài ra, việc đào tạo những kiến thức chuyên môn và kỹ năng làm việc nhóm cũng cần được quan tâm.

Nhiệm vu dụ án (NVDA) có tác động mạnh thứ ba lên sự thành công dự án $(\mathrm{H} 1)$ với hệ số $\beta=0,157$ và Sig. $=0,007<5 \%$. Bước đầu tiên của quá trình thực hiện là làm rõ các mục tiêu của dự án. Khi nhiệm vụ hay mục tiêu dự án được xác định rõ ràng, nhà quản lý dự án sẽ biết chính xác điều cần đạt được và liệu nó có phù hợp với mục tiêu và lợi ích của tổ chức không. Do đó, để xây dựng nhiệm vụ dự án phù hợp chiến lược của tổ chức, các phân tích SWOT (điểm mạnh, điểm yếu, cơ hội và thách thức) cần được thực hiện. Ngoài ra, tiêu chuẩn SMART (cụ thể, đo lường được, phân công được, có tính thực tiễn và có thời hạn) nên được áp dụng khi xây dựng nhiệm vụ dự án để thuận lợi cho việc triển khai sau này.

Giải quyết vấn đề (GQVĐ)có tác động mạnh thứ tư lên sự thành công của dự án (H8) với hệ số $\beta=0,137$ và $S i g .=0,013<5 \%$. Trong quá trình thực hiện dự án, việc xảy ra các vấn đề ngoài ý muốn là điều không thể tránh khỏi và khi đó khả năng giải quyết vấn đề của các thành viên trong nhóm dự án sẽ quyết định sự thành công hay thất bại của dự án. Do đó, các thành viên trong nhóm dự án cần được đào tạo kỹ năng giải quyết vấn đề phát sinh. Việc lập kế hoạch quản lý rủi ro trước khi triển khai dự án là cần thiết. Khi có những vấn đề phát sinh vượt ngoài khả năng giải quyết của các thành viên trong dự án thì các nhà quản lý dự án cần phải nhanh chóng yêu cầu sự trợ giúp từ phía nội bộ doanh nghiệp hoặc từ các nguồn lực bên ngoài để giải quyết triệt để những vấn đề này.

Công việc kỹ thuật (CVKT) có tác động mạnh thứ năm lên sự thành công của dự án (H6) với hệ số $\beta=0,133$ và Sig. $=0,020<5 \%$. Một dự án sản xuất có các công nghệ/kỹ thuật phù hợp, hay việc luôn sẵn sàng đầu tư các công nghệ/kỹ thuật mới cho dự án cùng với nhân sự nhóm dự án có đầy đủ năng lực công nghệ/kỹ thuật sẽ làm gia tăng sự thành công của dự án. Do đó, đối với công việc kỹ thuật, ban/nhóm quản lý dự án hay lãnh đạo tổ chức cần phải thường xuyên cập nhật những công nghệ/kỹ thuật mới nhất hiện có và xem xét việc ứng dụng những công nghệ/kỹ thuật mới này vào trong quá trình thực hiện dự án. Song song đó cần có chương trình tuyển dụng hoặc đào tạo cho nhân sự dự án có khả năng sử dụng các công nghệ/kỹ thuật mới này.

Truyền thông (TTDA) có tác động mạnh thứ sáu lên sự thành công của dự án (H7) với hệ số $\beta=0,108$ và $\mathrm{Sig}$. $=0,042<5 \%$. Ở đây truyền thông là việc trao đồi thông tin giữa các thành viên với nhau, hay truyền thông trong nội bộ trong tổ chức hoặc truyền thông từ dự án ra bên ngoài. Nếu việc truyền thông không hiệu quả sẽ dẫn đến tình trạng các thành viên trong và ngoài dự án không nắm rõ thông tin hoặc thông tin bị sai lệch và sẽ dẫn tới việc hành động không chính xác hoặc không đúng tiến độ, kết quả là ảnh hưởng đến vấn đề tài chính, tiến độ dự án cũng như lợi ích của các bên liên quan. Do đó, dựa trên ma trận trách nhiệm, ban/nhóm 
quản lý dự án cần xây dựng kênh truyền thông chính thức để có thể trao đổi thông tin giữa các thành viên với nhau, giữa dự án với nội bộ tổ chức và giữa dự án với bên ngoài tổ chức. Việc ứng dụng công nghệ thông tin trong tổ chức có thể giúp việc truyền thông hiệu quả.

Hỗ trợ của quản lý cấp cao (HTCC) có tác động mạnh thứ bảy lên sự thành công của dự án với hệ số $\beta=0,106$ và Sig. $=0,034<5 \%$. Việc quản lý cấp cao có sự hỗ trợ kịp thời và đầy đủ về ngân sách, nguồn lực hay tin tưởng và trao quyền cho nhóm dự án thì khả năng sự thành công của dự án sẽ cao hơn. Do đó, lãnh đạo tổ chức cần có sự cam kết hỗ trợ dự án, đặc biệt trong việc phân bổ nguồn lực, chia sẻ quyền hạn và trách nhiệm để các thành viên dự án dễ dàng triển khai các công việc của dự án.

Tham khảo ý kiến khách hàng (YKKH) có mức tác động thấp nhất lên sự thành công của dự án (H4) với hệ số $\beta=0,100$ và Sig. $=0,041<5 \%$. Việc thường xuyên trao đổi thông tin với khách hàng không chỉ giúp nhóm dự án hiểu rõ khách hàng mà còn nhận được sự đồng ý với những nội dung công việc cần thực hiện ở những bước tiếp theo của dự án. Điều này giúp tránh được mâu thuẫn giữa nhóm dự án với khách hàng ở giai đoạn cuối của dự án. Do đó, ban/nhóm quản lý dự án cần xây dựng mối quan hệ mật thiết với khách hàng. Mối quan hệ này sẽ giúp nhóm/ban quản lý dự án thường xuyên trao đổi và tham khảo ý kiến khách hàng trong quá trình thực hiện dự án. Điều này giúp nhóm dự án có những điều chỉnh kịp thời các yêu cầu của khách hàng.

\section{Kết luận}

Sự thành công của dự án là yêu cầu quan trọng của mọi tổ chức khi thực hiện dự án. Nếu các nhà quản lý dự án không chú ý đến việc xác định và quản lý các yếu tố quan trọng quyết định sự thành công của dự án, dự án sẽ phải đối mặt với nhiều khó khăn, thậm chí sẽ bị thất bại. Kết quả của nghiên cứu này chỉ ra rằng các yếu tố thành công quan trọng cần được các nhà quản lý dự án cũng như các tổ chức cần quan tâm là lập kế hoạch dự án, năng lực nhân sự, nhiệm vụ dự án, giải quyết vấn đề, công việc kỹ thuật, truyền thông, hỗ trợ của quản lý cấp cao, tham khảo ý kiến khách hàng.

Nghiên cứu này cũng còn một số hạn chế nhất định. Thứ nhất là các yếu tố thành công trong mô hình nghiên cứu chủ yếu dựa trên mô hình PIP của Slevin và Pinto (1986). Đây là mô hình kinh điển được sử dụng khá phổ biến, nhưng gần đây cũng có nhiều nghiên cứu bổ sung thêm các yếu tố thành công khác. Do đó, nghiên cứu tiếp theo cần bổ sung thêm các yếu tố khác ngoài mô hình PIP. Thứ hai là phạm vi khảo sát chỉ mới tập trung vào các doanh nghiệp sản xuất ở TP. HCM, Bình Dương và Đồng Nai, do đó cần mở rộng phạm vi khảo sát ở các địa phương khác để kết quả nghiên cứu có tính khái quát cao hơn. Cuối cùng là đề tài khảo sát nhiều ngành sản xuất khác nhau và số mẫu trong mỗi ngành khá nhỏ. Do đó, nghiên cứu tiếp theo có thể tăng số mẫu của mỗi ngành để có thể so sánh và tìm ra những điểm đặc trưng của từng ngành về các yếu tố thành công của dự án.

\section{Tài liệu tham khảo}

Adnan, H., Yusuwan, N. M., Yusuf, F., \& Bachik, F. (2014). Critical success factors for contractors. International Journal of Engineering and Technical Research, 2(2), 107113. 
Ahadzie, D., Proverbs, D., \& Olomolaiye, P. (2008). Critical success criteria for mass house building projects in developing countries. International Journal of Project Management, 26(6), 675-687.

Atkinson, R. (1999). Project management: Cost, time and quality, two best guesses and a phenomenon, its time to accept other success criteria. International Journal of Project Management, 17, 337-342.

Baccarini, D. (2009). Critical success factors in construction engineering projects: A case study. AIPM09 Refereed Paper, 1-14.

Chan, A. P. C., \& Chan, A. P. L. (2004). Key performance indicators for measuring construction success. Benchmarking: An International Journal, 11(2), 203-221.

Clarke, A. (1999). A practical use of key success factors to improve the effectiveness of project management. International Journal of Project Management, 17(3), 139-145.

Cooke-Davies, T. (2002). The "real" success factors in projects. International Journal of Project Management, 6(3), 164-170.

Fraz, A., Waris, M. A., Afzal, S., Jamil, M., \& Syed, T. H. (2016). Effect of project management practices on project success in make-to-order manufacturing organizations. Indian Journal of Science and Technology, 19(21), 1-8.

Hair, J. F., Black, W. C., Babin, B. J., \& Anderson, R. E. (2014). Multivariate data analysis (7th ed.). London, UK: Pearson Education Limited.

Iram, N., Khan, B., \& Sherani, A. W. (2016). Critical factors influencing the project success: An analysis of projects in manufacturing and construction in Pakistan. Arabian Journal of Business and Management Review, 6(2), 20-32.

Junior, A. C. P., Silva, S. L., \& Pacifico, O. (2017). Critical success factors and the "iron triangle": A study in project manufacturing environments. Proceedings of the 2017 International Conference on Industrial Engineering and Operations Management (IEOM), 24-25.

Kerzner, H. (1987). In search of excellence in project management. J-Systems Manage, 38(2), 30-40.

Kuen, C. W., Zailani, S., \& Fernando, Y. (2009). Critical factors influencing the project success amongst manufacturing companies in Malaysia. African Journal of Business Management, 3(1), 16-27.

Larson, E. W., \& Gray, C. F. (2018). Project management: The managerial process (7th ed.). New York, NY: McGraw-Hill Education.

Lynn, G. S., Skov, R. B., \& Abel, K. D. (1999). Practices that support team learning and their impact on speed to market and new product success. Journal of Production Innovation Management, 16(5), 439-454.

Minh Huyen (2017). Năm 2017, tập trung đẩy nhanh tiến độ thực hiện các dụ án công nghiệp đã đầu tu và đura vào sản xuất [In 2017, focus on accelerating the implementation of industrial projects that have been invested and put into production]. Retrieved June 20, 2019, from Quang Binh website: http://www.quangbinh.gov.vn 
Mobey, A., \& Parker, D. (2002). Risk evaluation and its importance to project implementation. International Journal of Productivity and Performance Management, 51(4), 202-208.

Muller, R., \& Turner, J. R. (2003). On the nature of the project as a temporary organization. International Journal of Project Management, 21(1), 1-8.

Muller, R., \& Turner, J. R. (2005). The project manager's leadership style as a success factor on project. Project Management Journal, 36(1), 49-61.

Pinto, J. K., \& Slevin, D. P. (1989). Critical success factors in R\&D projects. Research Technology Management, 32(1), 31-33.

Pinto, R., \& Dominguez, C. (2012). Characterization of the practice of project management in 30 Portuguese metalworking companies. International Conference on Health and Social Care Information Systems and Technologies, 5(1), 83-92.

Slevin, D. P., \& Pinto, J. K. (1986). The project implementation profile: New tool for project managers. Project Management Journal, 57-70.

Tổng cục Thống kê. (2018). Tổng quan kinh tế - xã hội Việt Nam năm 2018 [Socio-economic overview of Vietnam in 2018]. Retrieved June 16, 2019, from https://www.gso.gov.vn/default.aspx?tabid=382\&idmid=2\&ItemID=19041

Yeoh, W., \& Koronios, A. (2010). Critical success factors for business intelligence systems. Journal of Computer Information Systems, 50(3), 23-32. 